\title{
Gerakan Literasi Digital Berbasis Sekolah: Implementasi dan Strategi
}

\author{
Yolanda Presiana Desi \\ Sekolah Tinggi Multi Media "MMTC” Yogyakarta \\ J1. Magelang Km. 6 Yogyakarta 55284, Indonesia \\ Email: yola001@kominfo.go.id \\ * corresponding author
}

\begin{abstract}
This study aims to measure the digital literacy level of Karitas Ngaglik Sleman Junior High School students based on nine elements of digital literacy of Steve Wheeler; social networking, transliteracy, maintaining privacy, managing digital identity, creating content, organizing and sharing content, repurposing content, filtering and selecting content, self broadcasting; and to know how the school-based digital literacy movement is implemented. The research used is a concurrent embedded mixed method. The results show that the digital literacy level of the majority of Karitas Ngaglik Sleman Junior High School students was at the medium level and has the lowest score on the repurposing content element. The school-based digital literacy movement of Karitas Ngaglik Sleman Junior High School only applies several aspects among 3 indicators according to Ministry of Education and Culture. Referring to Mayes and Fowler, the schoolbased digital literacy movement has only been applied to level 1 (Digital Competence) and level 2 (Digital Usage). The contribution of this research provides input that the school-based digital literacy movement must be developed as an integrated learning mechanism in the curriculum that includes all 9 elements of digital literacy. Furthermore, training needs to be held for teachers as digital literacy actors/facilitators. The support from school principals and an active participation from parents are also needed to develop digital literacy culture at school. The school-based digital literacy movement should be developed to level 3 (Digital Transformation) to increase creativity and innovation of young people in the digital world.
\end{abstract} Keywords: digital literacy, school, students, internet

\begin{abstract}
Abstrak
Penelitian ini bertujuan untuk mengukur tingkat literasi digital pelajar SMP Karitas Ngaglik Sleman berdasarkan 9 elemen literasi digital menurut Steve Wheeler, yaitu: social networking, transliteracy, maintaning privacy, managing digital identity, creating content, organising and sharing content, repurposing content, filtering and selecting content, self broadcasting serta untuk mengetahui bagaimana gerakan literasi digital berbasis sekolah diterapkan. Penelitian ini menggunakan metode campuran embedded konkuren. Hasil penelitian menunjukkan bahwa tingkat literasi digital pelajar SMP Karitas Ngaglik Sleman mayoritas berada pada level medium dan memiliki skor paling rendah pada elemen repurposing content. Gerakan literasi digital berbasis sekolah di SMP Karitas Ngaglik Sleman hanya menerapkan beberapa aspek dari 3 indikator menurut Kemendikbud. Mengacu pada Mayes dan Fowler maka gerakan literasi digital berbasis sekolah yang diterapkan baru sampai pada level 1 (Digital Competence) dan level 2 (Digital Usage). Kontribusi penelitian ini berupa masukan kebijakan supaya gerakan literasi digital berbasis sekolah dikembangkan sebagai mekanisme pembelajaran yang terintegrasi dalam kurikulum serta mengacu pada keseluruhan 9 elemen literasi digital. Lebih lanjut, perlu diadakan pelatihan bagi guru sebagai pelaku/fasilitator literasi digital. Selain itu, dukungan dari kepala sekolah dan partisipasi aktif orang tua siswa diperlukan dalam mengembangkan budaya literasi digital di sekolah. Gerakan literasi digital berbasis sekolah perlu dikembangkan hingga level 3 (Digital Transformation) untuk menumbuhkan kreativitas dan inovasi generasi muda dalam dunia digital. Kata kunci: literasi digital, sekolah, pelajar, internet
\end{abstract}

\section{Pendahuluan}

Kemajuan teknologi dan informasi serta semakin canggihnya perangkat-perangkat yang diproduksi oleh industri seperti menghadirkan 'dunia dalam genggaman'. Istilah ini seperti yang dikemukakan oleh Thomas L. Friedman
(2007) sebagai 'the world is flat' bahwa dunia semakin rata dan setiap orang bisa mengakses apa pun dari sumber mana pun (Nasrullah, 2015: 1). Dikutip dari Kementerian Pendidikan dan Kebudayaan (2017) berkembangnya peralatan digital dan akses akan informasi dalam 
bentuk digital mempunyai peluang sekaligus tantangan. Dampak positif internet diantaranya adalah kecepatan akses informasi dan hiburan, kemudahan dalam berkomunikasi dan bertransaksi bisnis, serta pemerataan akses pendidikan. Sebaliknya, internet juga memiliki dampak negatif yang perlu diwaspadai. Kementerian Komunikasi dan Informatika selama tahun 2018 telah memblokir 961.456 situs internet yang memuat konten negatif. Kategori konten negatif itu antara lain pornografi, perjudian, pemerasan, penipuan, kekerasan, fitnah atau pencemaran nama baik, pelanggaran kekayaan intelektual, produk dengan aturan khusus, provokasi SARA, hoaks, terorisme atau radikalisme, serta informasi atau dokumen elektronik yang melanggar undang-undang lainnya (Kemenkominfo, 2018).

Hasil survey Asosiasi Penyelenggara Jasa Internet Indonesia tahun 2017 menyebutkan bahwa komposisi pengguna internet didominasi oleh generasi muda. Pengguna internet pada rentang usia 13-18 tahun mencapai $16,68 \%$ dan rentang usia 19-34 tahun mencapai 49,52\% dari total 143,26 juta jiwa pengguna internet di Indonesia. Penetrasi pengguna internet pada rentang usia 13-18 tahun (remaja) mencapai $75,5 \%$, paling tinggi dibanding rentang usia lainnya (APJII, 2017). Namun demikian, remaja cenderung mudah terpengaruh oleh lingkungan sosial tanpa mempertimbangkan terlebih dahulu efek positif atau negatif yang akan diterima saat melakukan aktivitas di internet (Ekasari dan Darmawan, 2012: 57). Kurnia dan Astuti (2017: 161) juga menyatakan bahwa kaum muda dianggap sebagai kelompok yang paling rentan dan dianggap paling banyak mendapatkan pengaruh buruk dari media digital. Atau sebaliknya, mereka dianggap sebagai agen perubahan yang diharapkan bisa turut ambil bagian dalam mengatasi berbagai persoalan masyarakat digital. Literasi digital merupakan hal penting yang dibutuhkan setiap individu untuk dapat berpartisipasi di dunia modern sekarang ini (Kemendikbud, 2017).
The United Nations Educational, Scientific, and Cultural Organization (UNESCO) baru menyentuh persoalan literasi digital pada bulan Mei 2007, setelah konferensi Lisbon (Kurnia dan Astuti, 2017). Bahkan literasi di era digital baru menjadi tema hari literasi internasional yang ditetapkan UNESCO pada tanggal 8 September 2017. UNESCO bertujuan untuk mencari tahu kemampuan literasi apa saja yang diperlukan masyarakat dalam menghadapi era digital dan mengeksplorasi program serta kebijakan di bidang literasi.

Istilah literasi digital awalnya digunakan pada tahun 1980-an ketika teknologi komputasi mulai digunakan untuk menunjang kehidupan sehari-hari (Widyastuti, et al., 2016: 5; Dini \& Lestari, 2015). Mengadopsi konsep literasi media menurut James Potter (2005) maka literasi digital adalah ketertarikan, sikap, dan kemampuan individu dalam menggunakan teknologi digital dan alat komunikasi untuk mengakses, mengelola, mengintegrasikan, menganalisis dan mengevaluasi informasi, membangun pengetahuan baru, membuat dan berkomunikasi dengan orang lain agar dapat berpartisipasi secara efektif dalam masyarakat. "A set of perspectives that we actively expose ourselvesto themediatointerpret the meaning of the messages we encounter. We build our perspectives from knowledge structures. To build our knowledge structures, we need tools and raw material. These tools are our skills. The raw material is information from the media and the real world. Active use means that we are aware of the messages and are consciously interacting with them." (Potter (2005) dalam Widyastuti, et al., 2016: 5)

Steve Wheeler (2012: 16) kemudian mengemukakan elemen penting literasi digital yang menyangkut kemampuan apa saja yang harus dikuasai dalam pemanfaatan tekonologi informasi dan komunikasi, yaitu: 1) social networking, 2) transliteracy, 3) maintaining privacy, 4) managing identity, 5) creating content, 6) organising and sharing content, 7) repurposing content, 8) filtering and selecting 
content, 9) self broadcasting. Social networking adalah keterampilan menggunakan berbagai layanan jaringan sosial. Transliteracy diartikan sebagai kemampuan menggunakan berbagai platform digital. Maintaining privacy yaitu kemampuan mengelola dan menjaga privasi data digital. Managing digital identity adalah kemampuan menggunakan identitas yang tepat di berbagai platform digital. Creating content yaitu kemampuan membuat konten yang sesuai di berbagai platform digital. Organising and sharing content adalah kemampuan mengatur dan berbagi konten secara tepat di berbagai platform digital. Repurposing content yaitu kemampuan menggunakan atau menggabungkan konten yang sudah ada untuk menghasilkan konten baru yang kreatif. Filtering and selecting content adalah kemampuan menyaring dan memilih konten yang tepat sesuai dengan kebutuhan. Self broadcasting merupakan kemampuan untuk membagikan konten pribadi dengan tepat.

Sekolah sebagai salah satu institusi pendidikan sesungguhnya memiliki peran strategis dalam mengajarkan literasi digital kepada generasi muda. Sayangnya, sekolah tidak banyak berkontribusi sebagai pelaku kegiatan literasi digital di Indonesia. Kurnia dan Astuti
(2017: 159) menyatakan bahwa perguruan tinggi $(56,14 \%)$ adalah pelaku utama kegiatan literasi digital yang disusul dengan pemerintah (14,34\%), komunitas (13,52\%), lembaga swadaya masyarakat $(5,32 \%)$, sekolah dan korporasi masing-masing $(3,68 \%)$, asosiasi profesi dan ormas $(2,86 \%)$, media $(0,4 \%)$, lain-lain $(2,86 \%)$. Literasi digital berbasis sekolah sesungguhnya sudah ada sejak mata pelajaran Teknologi Informasi dan Komunikasi (TIK) menjadi bagian dari Kurikulum 2006 atau KTSP. Namun mata pelajaran tersebut dihilangkan dari Kurikulum 2013 dengan alasan bahwa pembelajaran TIK dapat diintegrasikan pada mata pelajaran lainnya. Di tahun 2017 gerakan literasi digital berbasis sekolah disematkan dalam Gerakan Literasi Nasional (GLN) oleh Kementerian Pendidikan dan Kebudayaan. Tingkat literasi digital mengacu pada dimensi individual yang disusun oleh European Association for Viewers's Interests (2009: 55) seperti pada tabel 1. Penelitian ini bertujuan untuk mengetahui bagaimanagerakanliterasidigitalberbasissekolah diterapkan di SMP Karitas Ngaglik Sleman berdasarkan indikator literasi digital di sekolah menurut Kemendikbud (2017) yang berbasis pada kelas, budaya sekolah, dan masyarakat.

Tabel 1. Level Kompetensi

\begin{tabular}{|c|c|}
\hline Level & Definisi Menurut Dimensi Individual \\
\hline Basic & $\begin{array}{l}\text { Individu memiliki kemampuan penggunaan dasar media yang terbatas. Pengguna } \\
\text { mengetahui fungsi dasar media dan menggunakannya untuk tujuan tertentu. } \\
\text { Pengguna memiliki kemampuan yang terbatas dalam menganalisa informasi secara } \\
\text { kritis serta memiliki kemampuan berkomunikasi yang terbatas. }\end{array}$ \\
\hline Medium & $\begin{array}{l}\text { Individu memiliki tingkatan menengah dalam penggunaan media, mengetahui } \\
\text { fungsi media secara lebih mendalam dan mampu mengoperasikan media dengan } \\
\text { lebih kompleks. Pengguna tahu cara mendapatkan dan mengevaluasi informasi yang } \\
\text { dibutuhkan serta dapat mengevaluasi strategi pencarian informasi. Pengguna aktif } \\
\text { memproduksi konten dan berpartisipasi secara sosial. }\end{array}$ \\
\hline Advanced & $\begin{array}{l}\text { Individu sangat ahli dalam penggunaan media serta menyadari etika dan konsekuensi } \\
\text { hukum bagi penggunanya. Pengguna memiliki pengetahuan dan mampu melakukan } \\
\text { analisis mendalam tentang teknik dan bahasa di media serta mampu mengubah } \\
\text { kondisi yang mempengaruhi hubungan komunikatif dalam memproduksi dan } \\
\text { mengkomunikasikan pesan. Di ruang publik, pengguna mampu menggerakkan } \\
\text { kerjasama kelompok untuk memecahkan suatu permasalahan. }\end{array}$ \\
\hline
\end{tabular}

Sumber: EAVI, (2009) 


\section{Metode Penelitian}

Penelitian ini menggunakan metode campuran embedded konkuren (embedded concurrent mixed methods) dimana peneliti mempertemukan data kuantitatif dan kualitatif untuk memperoleh analisis komprehensif atas masalah penelitian. Menurut Cresswell (2010: 322), data kuantitatif dan kualitatif dapat dideskripsikan secara berdampingan sebagai dua gambaran berbeda yang merepresentasikan penilaian gabungan terhadap suatu masalah. Data kuantitatif digunakan untuk mengukur tingkat literasi digital pelajar di SMP Karitas Ngaglik Sleman dengan menggunakan teknik analisis data distribusi frekuensi. Sedangkan data kualitatif digunakan untuk mengetahui implementasi gerakan literasi digital berbasis sekolah di SMP Karitas Ngaglik Sleman berdasarkan indikator literasi digital di sekolah menurut Kemendikbud (2017) yang berbasis pada kelas, budaya sekolah, dan masyarakat. Data kemudian dianalisis melalui tahapan reduksi data, penyajian data, dan penarikan kesimpulan menurut Miles dan Huberman (2007).

\section{Hasil Penelitian dan Pembahasan Tingkat Literasi Digital}

SMP Karitas Ngaglik Sleman merupakan sekolah menengah pertama swasta berbasis agama Katolik yang diperuntukkan untuk umum. SMP ini berdiri sejak 1 Januari 1968 dan berada di bawah pengelolaan Yayasan Karya Bakti Cabang Yogyakarta bersama dengan TK dan SD Karitas. Sekolah ini menganut pendidikan heterogen dengan komposisi siswa berjumlah 70 orang yang terdiri dari 18 siswa kelas VII,
13 siswa kelas VIII, dan 39 siswa kelas IX. Mereka berasal dari berbagai latar belakang agama Katolik, Kristen, dan Islam serta dari berbagai daerah di Jawa dan Papua melalui program Afirmasi Pendidikan Menengah (ADEM) yang dicanangkan oleh Kemendikbud. SMP Karitas Ngaglik Sleman masih menggunakan Kurikulum 2006 atau KTSP.

Dari 55 orang responden siswa SMP Karitas Ngaglik Sleman Tahun Ajaran 2017-2018, tingkat literasi digital siswanya mayoritas berada di level medium. Sebanyak 12 siswa (22\%) berada pada level basic, 37 siswa (67\%) berada pada level medium, dan hanya 6 siswa $(11 \%)$ berada pada level advanced. Sebanyak 22\% siswa berada pada level basic mengindikasikan bahwa sebagian kecil siswa memiliki kemampuan literasi media pada tataran dasar, memiliki kemampuan penggunaan dasar media digital yang terbatas, mengetahui fungsi dasar media digital dan menggunakannya untuk tujuan tertentu, memiliki kemampuan yang terbatas dalam menganalisa informasi secara kritis, serta memiliki kemampuan berkomunikasi yang terbatas dalam media digital. Mayoritas siswa (67\%) berada pada level medium menandakan bahwa mayoritas siswa memiliki tingkatan menengah dalam penggunaan media digital, mengetahui fungsi media digital secara lebih mendalam, mampu mengoperasikan media digital dengan lebih kompleks, mengetahui cara mendapatkan dan mengevaluasi informasi yang dibutuhkan, dapat mengevaluasi strategi pencarian informasi, serta telah aktif dalam produksi konten dan partisipasi di media digital. Hanya sedikit siswa yang berada pada level

Tabel 2. Tingkat Literasi Digital

\begin{tabular}{cccc}
\hline Kategori & Skor & Frekuensi & Prosentase \\
\hline Basic & $30-49$ & 12 & $22 \%$ \\
Medium & $50-69$ & 37 & $67 \%$ \\
Advanced & $70-90$ & 6 & $11 \%$ \\
Jumlah & & 55 & $100 \%$ \\
\hline
\end{tabular}

Sumber: Olahan peneliti, (2017) 


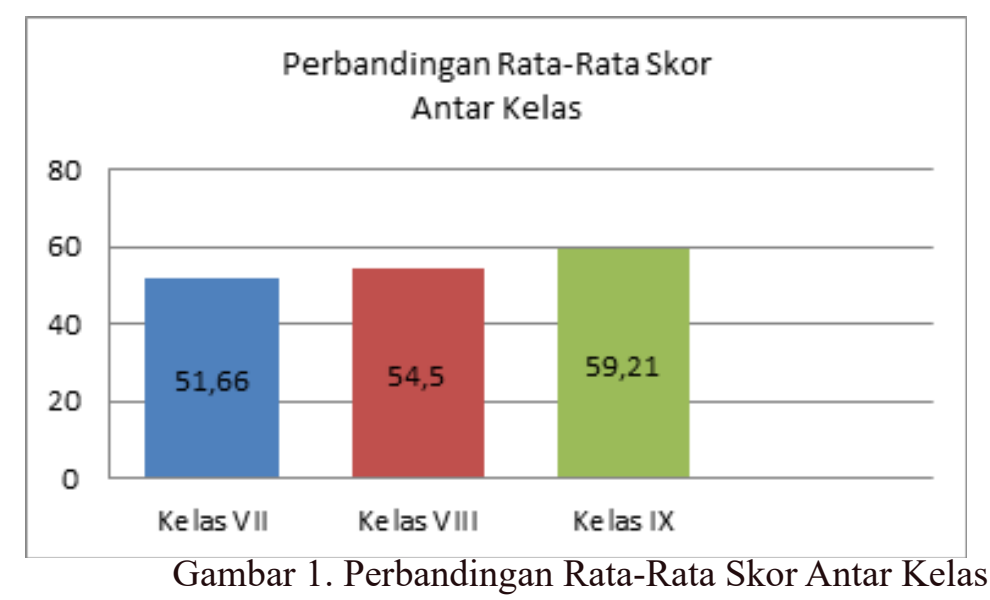

Sumber: Olahan peneliti, (2017)

advanced (11\%) yang berarti bahwa hanya sedikit siswa yang sangat ahli dalam penggunaan media digital serta menyadari etika dan konsekuensi hukum bagi penggunanya, memiliki pengetahuan dan mampu melakukan analisis mendalam tentang teknik dan bahasa di media digital, mampu mengubah kondisi yang mempengaruhi hubungan komunikatif dalam memproduksi dan mengkomunikasikan pesan, serta mampu menggerakkan kerjasama kelompok di media digital untuk memecahkan suatu permasalahan.

Jika dilihat dari perbandingan rata-rata skor masing-masing kelas, kelas IX memiliki tingkat literasi digital paling tinggi dibandingkan kelas lainnya seperti pada gambar 1. Hal tersebut dapat disebabkan oleh beberapa kemungkinan. Pertama, siswa kelas IX lebih matang secara usia dibandingkan kelas VII dan VIII. Jika dilihat dari tahapan usia remaja menurut Lerner dan Steinberg (2011: 5) siswa kelas IX berada pada tahap middle adolescence (14-17 tahun) sedangkan siswa kelas VII dan VIII berada pada tahap early adolescence (10-13 tahun). Kedua, siswa kelas IX sebagai kelas tertinggi di Sekolah Menangah Pertama memiliki pengetahuan dan keterampilan yang lebih kompleks dibandingkan siswa kelas VII dan VIII.

Merujuk pada 9 elemen literasi digital menurut Steve Wheeler (2012: 16) yaitu social networking, transliteracy, maintaning privacy, managing digital identity, creating content, organising and sharing content, repurposing content, filtering and selecting content, dan self broadcasting, maka perbandingan skor masingmasing elemen literasi digital sebagai gambar 2 .

Hal yang perlu digarisbawahi dari temuan data di atas adalah elemen repurposing content memiliki skor paling rendah yaitu 1,59. Hal tersebut mengindikasikan rendahnya kemampuan siswa dalam menggunakan atau menggabungkan konten yang sudah ada untuk menghasilkan konten baru yang kreatif. Temuan ini senada dengan hasil penelitian Siberkreasi dan Kementerian Kominfo tentang indeks literasi digital remaja di kota besar di Indonesia. Pada penelitian fase pertama periode September-November 2018, Siberkreasi mengumpulkan 2.000 responden remaja dengan rentang usia 13-18 tahun di 4 kota, yaitu Bandung, Surabaya, Pontianak, dan Denpasar. Hasil survei menunjukkan bahwa komponen kreatifitas mendapat persentase paling rendah dibandingkan komponen literasi digital lain (Kemenkominfo, 2018). Kemendikbud (2017) juga memacu generasi muda untuk beralih dari konsumen informasi yang pasif menjadi produsen aktif, baik secara individu maupun sebagai bagian dari komunitas.

\section{Gerakan Literasi Digital Berbasis Sekolah}

Konsep literasi digital, sejalan dengan terminologi yang dikembangkan oleh UNESCO pada tahun 2011, yaitu merujuk pada serta tidak bisa dilepaskan dari kegiatan literasi, seperti 


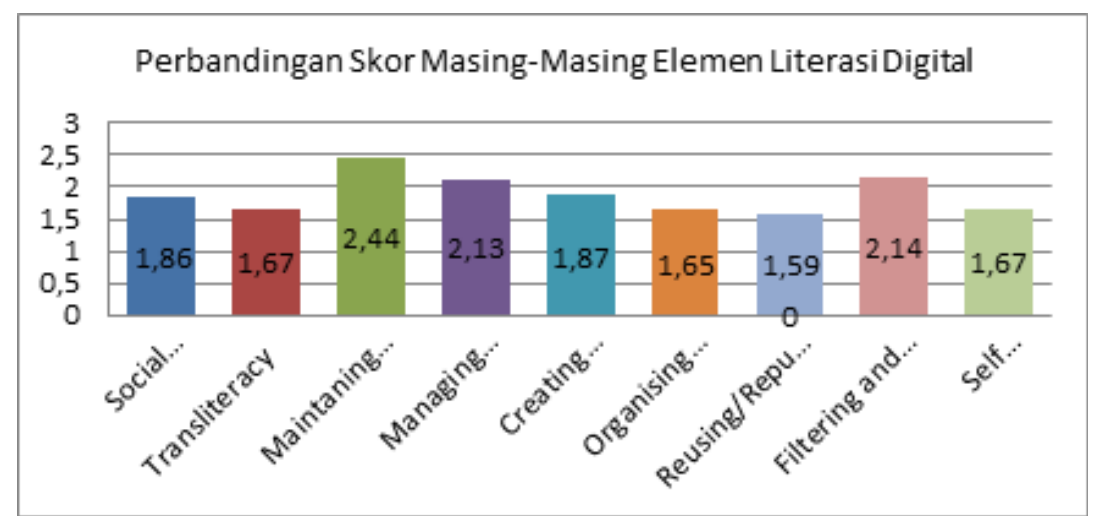

Gambar 2. Perbandingan Skor Masing-Masing Elemen Literasi Digital

Sumber: Olahan peneliti, (2017)

membaca dan menulis, serta matematika yang berkaitan dengan pendidikan (Kemendikbud, 2017). Literasi digital berbasis sekolah sesungguhnya sudah ada sejak mata pelajaran Teknologi Informasi dan Komunikasi (TIK) menjadi bagian dari Kurikulum 2006 atau KTSP. Namun mata pelajaran tersebut dihilangkan dari Kurikulum 2013 dengan alasan bahwa pembelajaran TIK dapat diintegrasikan pada mata pelajaran lainnya. Di tahun 2017 gerakan literasi digital berbasis sekolah disematkan dalam Gerakan Literasi Nasional (GLN) oleh Kementerian Pendidikan dan Kebudayaan. Sayangnya, sekolah sebagai salah satu institusi pendidikan tidak banyak berkontribusi sebagai pelaku kegiatan literasi digital. Kurnia dan Astuti (2017: 159) menyatakan bahwa perguruan tinggi (56,14\%) adalah pelaku utama kegiatan literasi digital yang disusul dengan pemerintah (14,34\%), komunitas $(13,52 \%)$, lembaga swadaya masyarakat (5,32\%), sekolah dan korporasi masing-masing (3,68\%), asosiasi profesi dan ormas $(2,86 \%)$, media $(0,4 \%)$, lain-lain $(2,86 \%)$.

Literasi digital di sekolah menurut Kemendikbud (2017) memiliki 3 indikator berbasis kelas, budaya sekolah, dan masyarakat. Indikator literasi digital di sekolah berbasis kelas meliputi aspek: a) Jumlah pelatihan literasi digital yang diikuti oleh kepala sekolah, guru, dan tenaga kependidikan; b) Intensitas penerapan dan pemanfaatan literasi digital dalam kegiatan pembelajaran; dan c) Tingkat pemahaman kepala sekolah, guru, tenaga kependidikan, dan siswa dalam menggunakan media digital internet. Indikator literasi digital di sekolah berbasis budaya sekolah meliputi aspek: 1) Jumlah dan variasi bahan bacaan dan alat peraga berbasis digital; 2) Frekuensi peminjaman buku bertema digital; 3) Jumlah kegiatan di sekolah yang memanfaatkan teknologi dan informasi; 4) Jumlah penyajian informasi sekolah dengan menggunakan media digital atau situs laman; 5) Jumlah kebijakan sekolah tentang penggunaan dan pemanfaatan teknologi informasi dan komunikasi di lingkungan sekolah; dan 6) Tingkat pemanfaatan dan penerapan teknologi informasi dan komunikasi dalam hal layanan sekolah (misalnya, rapor-e, pengelolaan keuangan, dapodik, pemanfaatan data siswa, profil sekolah, dsb). Sedangkan indikator literasi digital di sekolah berbasis masyarakat meliputi aspek: 1) Jumlah sarana dan prasarana yang mendukung literasi digital di sekolah; dan 2) Tingkat keterlibatan orang tua, komunitas, dan lembaga dalam pengembangan literasi digital.

Gerakan literasi digital berbasis sekolah di SMP Karitas Ngaglik Sleman jika dianalisis berdasarkan indikator basis kelas dari Kemendikbud (2017) hanya meliputi penerapan dan pemanfaatan literasi digital dalam beberapa mata pelajaran. Kegiatan literasi digital muncul atas inisiatif guru-guru pengampu mata pelajaran Bahasa Indonesia, Bahasa Inggris, Matematika, IPA, IPS, dan 
TIK. Pada aspek tingkat pemahaman guru, konsep literasi digital lebih menekankan pada aspek kognitif serta kompetensi teknis dalam pengoperasikan piranti keras dan piranti lunak. Pada mata pelajaran TIK kelas VII-IX, kegiatan literasi digital lebih menekankan pada aspek kognitif dan kompetensi teknis siswa seperti: 1) Definisi dan sejarah perkembangan TIK, 2) Sistem operasi, 3) Perangkat keras (Hardware) 4) Perangkat lunak (Software), 5) Mesin pencari informasi, dan 6) Surat elektronik dan blog. Hanya sedikit materi pelajaran yang mengulas tentang peran dan dampak TIK serta korelasi kehadiran internet dan masyarakat. Walaupun demikian, kegiatan literasi digital pada mata pelajaran TIK tidak hanya sebatas pada aspek kognitif dan teknis tetapi sudah diarahkan pada aspek produksi konten melalui penugasan menulis artikel di blog pribadi siswa, walaupun masih minim.

Pada mata pelajaran IPS, kegiatan literasi digital dilakukan melalui penugasan mencari literatur di internet. Pada mata pelajaran Bahasa Inggris, dilakukan melalui penugasan mencari literatur di internet serta penugasan membuat video drama kelompok. Hasil tugas kemudian dikirimkan oleh siswa melalui email kepada guru pengampu. Pada mata pelajaran IPA, kegiatan literasi digital dilakukan melalui penugasan membuat video drama kelompok bertema sistem peredaran darah. Siswa-siswa bermain peran sebagai jantung, pembuluh darah, paru-paru, sel-sel darah, dan organ tubuh lainnya. Video kemudian diunggah melalui akun Facebook milik guru pengampu.

Pada mata pelajaran matematika aritmatika sosial yang membahas tentang harga penjualan, harga pembelian, laba, dan rugi, kegiatan literasi digital dilakukan melalui praktek video wawancara siswa dengan pedagang di pasar. Hasil rekaman video kemudian diunggah di blog pribadi siswa. Pada mata pelajaran Bahasa Indonesia, dilakukan melalui penugasan mencari literatur di internet serta penugasan membuat film dokumenter pendek yang mengangkat berbagai topik sesuai dengan materi di kelas. Salah satunya hasil produksi siswa adalah film berjudul "Jawa vs Papua". Film yang diunggah di internet ini menceritakan indahnya kebersamaan siswa-siswa SMP Karitas Ngaglik Sleman dalam keberagaman suku, agama, dan budaya. Film dokumenter pendek ini meraih penghargaan sebagai Juara I kompetisi film tingkat pelajar SMP yang diadakan oleh SMP BOPKRI Yogyakarta pada tahun 2016. Film ini juga sering diputar dalam kegiatan promosi sekolah.

Gerakan literasi digital berbasis sekolah di SMP Karitas Ngaglik Sleman jika dianalisis berdasarkan indikator basis budaya sekolah dari Kemendikbud (2017) hanya menerapkan sedikit kebijakan sekolah tentang penggunaan dan pemanfaatan teknologi informasi dan komunikasi

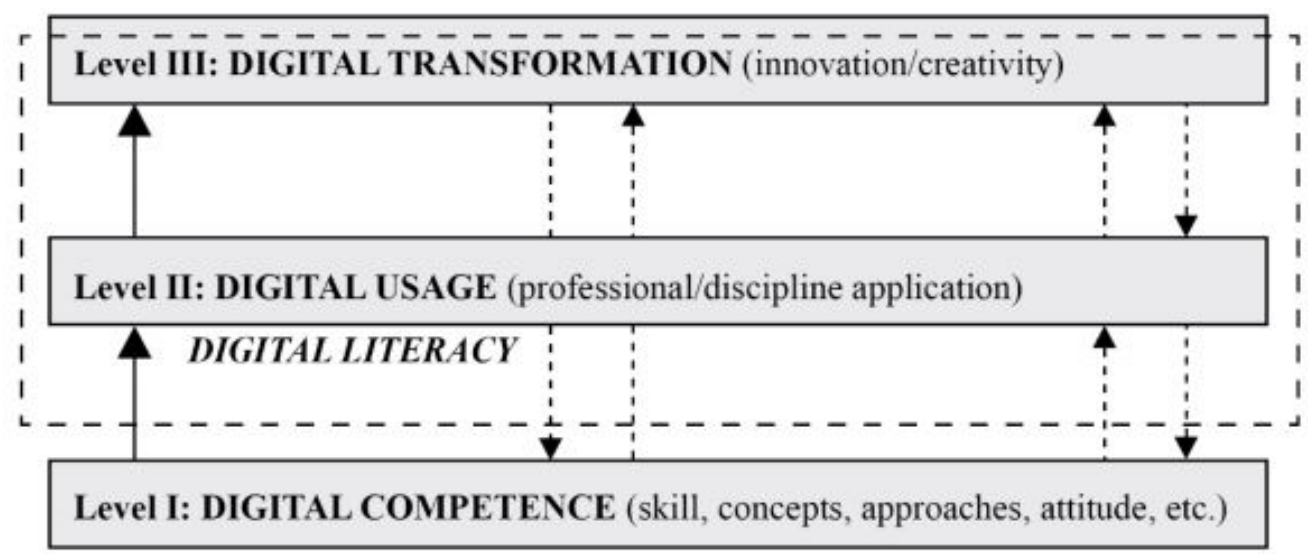

Gambar 3. Prinsip Pengembangan Literasi Digital Menurut Mayes dan Fowler Sumber: Kemendikbud, (2017) 
di lingkungan sekolah. Misalnya melalui pembuatan BlackBerry Messanger (BBM) Group pada tahun 2015. BBM Group ini menjadi sarana komunikasi antar siswa dengan wali murid. Di tahun 2016 dengan semakin dikenalnya aplikasi WhatsApp Messenger, dibuatlah WhatsApp Grup untuk memudahkan komunikasi antar siswa dan guru. Melalui BBM Group dan WhatsApp Group, pihak sekolah membangun budaya etika berinternet (netiket) yang baik. Pada tahun 2015 terjadi kasus perundungan siber (cyberbullying) yang berawal dari ejek-ejekan antar siswa di BBM Group. Pihak sekolah kemudian menindak tegas pelaku cyberbulying dengan memberi hukuman disiplin. Belajar dari kejadian tersebut, siswa memahami pentingnya netiket serta memahami implikasinya terhadap diri sendiri, keluarga, lingkungan, dan masyarakat.

Gerakan literasi digital berbasis sekolah di SMP Karitas Ngaglik Sleman jika dianalisis berdasarkan indikator basis masyarakat dari Kemendikbud (2017) baru mencapai tingkat keterlibatan orang tua siswa yang terbatas. Proses pembelajaran siswa di sekolah menggunakan berbagai media digital pernah mendapat kritik dari orang tua siswa yang mayoritas berasal dari keluarga kurang mampu. Awalnya beberapa orang tua siswa beranggapan bahwa sekolah mewajibkan masing-masing siswa memiliki laptop, kamera, dan handphone. Setelah dilakukan pertemuan antara pihak sekolah, orang tua siswa memahami bahwa peralatan yang dibutuhkan seperti laptop, kamera, maupun handphone dapat dipakai bersama-sama dengan kelompok. Orang tua siswa juga memahami bahwa kegiatan literasi digital yang dilakukan bertujuan untuk mendukung proses belajar mengajar.

Menurut Mayes dan Fowler (2006) dalam Kemendikbud (2017), terdapat tiga tingkatan prinsip pengembangan literasi digital. Pertama, kompetensi digital yang meliputi keterampilan, konsep, pendekatan, dan perilaku. Kedua, penggunaan digital yang merujuk pada pengaplikasian kompetensi digital yang berhubungan dengan konteks tertentu. Ketiga, transformasi digitalyangmembutuhkan kreativitas dan inovasi pada dunia digital. Gerakan literasi digital berbasis sekolah yang diterapkan di SMP Karitas Ngaglik Sleman baru sampai pada level 1 (Digital Competence) dan level 2 (Digital Usage).

\section{Simpulan}

Penelitian tentang gerakan literasi digital berbasis sekolah di SMP Karitas Ngaglik Sleman menghasilkan beberapa kesimpulan. Pertama, tingkat literasi digital siswa mayoritas berada pada level medium. Hal ini menandakan bahwa mayoritas siswa memiliki tingkatan menengah dalam penggunaan media digital, mengetahui fungsi media digital secara lebih mendalam, mampu mengoperasikan media digital dengan lebih kompleks, mengetahui cara mendapatkan dan mengevaluasi informasi yang dibutuhkan, dapat mengevaluasi strategi pencarian informasi, serta telah aktif dalam produksi konten dan partisipasi di media digital. Kedua, merujuk pada 9 elemen literasi digital menurut Steve Wheeler, skor paling rendah pada elemen repurposing content. Hal ini berarti rendahnya kemampuan siswa dalam menggunakan atau menggabungkan konten yang sudah ada untuk menghasilkan konten baru yang kreatif. Ketiga, ditinjau dari 3 indikator gerakan literasi digital berbasis sekolah menurut Kemendikbud, gerakan literasi digital berbasis sekolah di SMP Karitas Ngaglik Sleman hanya menerapkan beberapa aspek. Pada indikator basis kelas, gerakan literasi digital berbasis sekolah di SMP Karitas Ngaglik Sleman hanya meliputi penerapan dan pemanfaatan literasi digital dalam beberapa mata pelajaran (Bahasa Indonesia, Bahasa Inggris, Matematika, IPA, IPS, dan TIK) atas inisiatif guru pengampu mata pelajaran. Selain itu, pemahaman guru tentang konsep literasi digital lebih menekankan pada aspek kognitif serta kompetensi teknis dalam pengoperasikan piranti keras dan piranti lunak. Pada indikator basis budaya sekolah, gerakan literasi digital berbasis sekolah hanya 
menerapkan sedikit kebijakan sekolah tentang penggunaan dan pemanfaatan teknologi informasi dan komunikasi di lingkungan sekolah melalui pembuatan BBM Group dan WhatsApp Group. Pada indikator basis masyarakat, gerakan literasi digital berbasis sekolah baru mencapai tingkat keterlibatan orang tua siswa yang terbatas. Keempat, mengacu pada prinsip pengembangan literasi digital menurut Mayes dan Fowler (2006) maka gerakan literasi digital berbasis sekolah yang diterapkan di SMP Karitas Ngaglik Sleman baru sampai pada level 1 (Digital Competence) dan level 2 (Digital Usage).

Berdasarkan simpulan penelitian maka kontribusi penelitian ini berupa: Pertama, masukan kebijakan supaya gerakan literasi digital berbasis sekolah dikembangkan sebagai mekanisme pembelajaran yang terintegrasi dalam kurikulum atau setidaknya terkoneksi dengan sistem belajar mengajar serta mengacu pada keseluruhan 9 elemen literasi digital. Kedua, perlu diadakan pelatihan bagi guru sebagai pelaku atau fasilitator literasi digital berbasis sekolah untuk meningkatkan pengetahuan, keterampilan, dan kreativitas dalam proses belajar mengajar. Ketiga, perlu dukungan dari kepala sekolah dan partisipasi aktif orang tua siswa dalam mengembangkan budaya literasi digital berbasis sekolah. Keempat, mengacu pada prinsip pengembangan literasi digital menurut Mayes dan Fowler (2006) maka gerakan literasi digital berbasis sekolah perlu dikembangkan hingga level 3 (Digital Transformation) untuk menumbuhkan kreativitas dan inovasi generasi muda dalam dunia digital.

\section{Ucapan Terima Kasih}

Penelitian ini dapat diselesaikan atas bantuan dan kerjasama dari berbagai pihak. Untuk itu penulis mengucapkan terima kasih kepada jajaran manajemen Sekolah Tinggi Multi Media "MMTC" Yogyakarta, Jaringan Pegiat Literasi Digital (Japelidi), serta pengelola SMP Karitas Ngaglik Sleman.

\section{Daftar Pustaka}

APJII. (2017). Infografis: Penetrasi dan Perilaku Pengguna Internet Indonesia 2017. Jakarta: Asosiasi Pengguna Jasa Internet Indonesia. Creswell, John W. (2010). Research Design: Pendekatan Kualitatif, Kuantitatif, dan Mixed. Yogyakarta: Pustaka Pelajar. Dini, C. P., \& Lestari, P. (2015). Literasi informasi tentang kemasan produk obat bebas. Jurnal ASPIKOM, 2(5), 357-373. EAVI, et.al. (2009). Studyon Assessment Criteriafor Media Literacy Levels: Final Report. Brussels: European Association for Viewers's Interests. Ekasari, P., dan Dharmawan, A. H. (2012). Dampak Sosial-Ekonomi Masuknya Pengaruh Internet Dalam Kehidupan Remaja di Pedesaan. Jurnal Sodality Institut Pertanian Bogor, 6(1), 57-71. Kemendikbud. Materi Pendukung Literasi Digital. (2017). Jakarta: Kementerian Pendidikan dan Kebudayaan.

Kurnia, Novi dan Astuti, Santi Indra. (2017). Peta Gerakan Literasi Digital di Indonesia: Studi tentang Pelaku, Ragam Kegiatan, Kelompok Sasaran, dan Mitra yang Dilakukan oleh JAPELIDI. Jurnal Informasi Universitas Negeri Yogyakarta, 47(2),149-166. Lerner, Richard M. dan Steinberg, Laurence. (2011). Adolescence $10^{\text {th }}$ Edition. New York: McGrawHill. Miles, B. Mattew dan Huberman, A. Michael. (2007). Analisis Data Kualitatif: Buku Sumber Tentang Metode-Metode Baru. Jakarta: Universitas Indonesia Press. Nasrullah, Rulli. (2015). Media Sosial: Perspektif Komunikasi, Budaya, dan Sosioteknologi. Bandung: PT Remaja Rosdakarya. Wheeler, Steve. (2012). Digital Literacies for Engagement in Emerging Online Cultures. eLC Research Paper Series, 5, 14-25. Widyastuti, Dhyah Ayu Retno et al. (2016). Literasi Digital pada Perempuan Pelaku Usaha Produktif di Daerah Istimewa Yogyakarta. Jurnal ASPIKOM, 3(1),1-15. www. kominfo.go.id 